\title{
Gender-specific association of TSNAX/DISC1 locus for schizophrenia and bipolar affective disorder in South Indian population
}

\author{
Anjanappa Ram Murthy ${ }^{1}$, Meera Purushottam ${ }^{1}$, Halagur Bhoge Gowda Kiran Kumar ${ }^{1}$, Manduva ValliKiran ${ }^{1}$, \\ Nithin Krishna ${ }^{1}$, Kallahalli Jayramu Sriharsha ${ }^{1}$, Yemmiganur Chandrashekar Janardhan Reddy ${ }^{1}$, \\ Saurabh Ghosh ${ }^{2}$ and Sanjeev Jain ${ }^{1}$
}

Genetic association studies have implicated the TSNAX/DISC1 (disrupted in schizophrenia 1) in schizophrenia (SCZ), bipolar affective disorder (BPAD) and major depression. This study was performed to assess the possible involvement of TSNAX/DISC1 locus in the aetiology of BPAD and SCZ in the Southern Indian population. We genotyped seven single nucleotide polymorphism (SNPs) from TSNAX/DISC1 region in 1252 individuals (419 BPAD patients, 408 SCZ patients and 425 controls). Binary logistic regression revealed a nominal association for rs821616 in DISC1 for BPAD and also combined cases of BPAD or SCZ, but after correcting for multiple testing, these results were non-significant. However, significant association was observed with BPAD, as well as combined cases of BPAD or SCZ, within the female subjects for the rs766288 after applying false discovery rate corrections at the 0.05 level. Two-locus analysis showed C-C (rs766288-rs2812393) as a risk combination in BPAD, and G-T (rs2812393-rs821616) as a protective combination in SCZ and combined cases of BPAD or SCZ. Female-specific associations were observed for rs766288-rs2812393, rs766288-rs821616 and rs8212393-rs821616 in two-locus analysis. Our results provide further evidence for sex-dependent effects of the TSNAX/DISC1 locus in the aetiology of SCZ and BPAD.

Journal of Human Genetics (2012) 57, 523-530; doi:10.1038/jhg.2012.62; published online 7 June 2012

Keywords: bipolar affective disorder; DISC1; Schizophrenia; TSNAX.

\section{INTRODUCTION}

Schizophrenia (SCZ) and bipolar affective disorder (BPAD) are severe psychiatric disorders, each affecting approximately $1 \%$ of the population worldwide. ${ }^{1}$ Family, twin and adoption studies confirm that genetic factors have a significant role in the aetiology of these disorders. $^{2}$ Several putative susceptibility loci and genes have been implicated, of which the TSNAX/DISC1 locus has shown encouraging results. The gene disrupted in schizophrenia 1 (DISC1) was first identified in a large Scottish family with a balanced translocation $\mathrm{t}(1$, 11) (q42.2, q14.3) segregating with major mental illness, including SCZ, BPAD and recurrent major depression. ${ }^{3-5}$ The translinassociated factor X (TRAX; TSNAX) gene is located adjacent to the DISC1 towards the $5^{\prime}$ region.

Subsequently several linkage studies have observed linkage near 1q42, which harbours DISC1, to SCZ ${ }^{6-9}$ and BPAD. ${ }^{10-12}$ Several population-based and family-based association studies have supported the role of the TSNAX/DISC1 locus in SCZ and/or BPAD in Caucasian ${ }^{13-25}$ and Asian ${ }^{26-28}$ populations. However, other studies have failed to replicate association between TSNAX/DISC1 and SCZ/BPAD. ${ }^{29-34}$ Recent meta-analysis found no evidence of association with SCZ with the variants in the DISC1. ${ }^{35}$ A metaanalysis of nine European studies has supported common SCZ risk interval within DISCl intron 4-6 with $P=0.002$, odds ratio $=1.27$. $^{24}$ There is also evidence for DISC1 being associated with poorer performance of visual attention and working memory. 16,26,36-38 Association of DISC1 with psychosis-related traits has been reported in Finnish population. ${ }^{39}$ A genome-wide association study has shown nominal association for SCZ with the SNPs near the DISC1 translocation break point. ${ }^{40}$ These results support a role for TSNAX/DISC1 genetic variation in conferring susceptibility to both SCZ and BPAD. Variation at the TSNAX/DISC1 region thus may have a role in susceptibility to severe psychiatric illness, though the risk variants are not clearly defined, and the haplotypes vary across populations.

Several reviews of the genetic epidemiology and molecular linkage studies suggest an overlap between genetic susceptibility to SCZ and $\mathrm{BPAD},{ }^{41-43}$ indicating that these two diagnostic categories may share risk factors. The TSNAX/DISC1 locus could be one of these

${ }^{1}$ Department of Psychiatry, Molecular Genetics Laboratory, National Institute of Mental Health and Neuro Sciences (NIMHANS), Bangalore, India and ${ }^{2}$ Human Genetics Unit, Indian Statistical Institute (ISI), Kolkata, India

Correspondence: Professor S Jain, Department of Psychiatry, Molecular Genetics Laboratory, National Institute of Mental Health and Neuro Sciences (NIMHANS), Bangalore 560029, India.

E-mail: sjain.nimhans@gmail.com

Received 5 January 2012; revised 4 May 2012; accepted 7 May 2012; published online 7 June 2012 
overlapping genetic susceptibility regions for psychosis. This is also supported by the observation that the translocation was found in both BPAD and SCZ phenotypes in the Scottish family, and a previous study $^{13}$ in this region has shown association with a combined phenotype of SCZ and BPAD, along with schizoaffective disorder, SCZ spectrum diagnosis.

The full-length human DISC1 protein (854 amino acids) is predicted to consist of an N-terminal region, often referred to as the globular 'head' domain and an alpha-helical coiled-coil-containing C-terminal region. ${ }^{4,44}$ DISC1 protein interacts with several proteins, which are involved in neuronal migration, cytoskeleton associated movements, cell cycle, signal transduction, intracellular transport/exocytosis, golgi and central nervous system development. ${ }^{45-47}$ The TSNAX (290 amino acids) protein has an important role in brain development by forming brain-enriched complexes with the protein, Translin. ${ }^{48}$ There is evidence of intergenic splicing and formation of fusion transcripts between TSNAX and DISC1. Five species of transcripts resulting from intergenic splicing have been identified, of which one encodes a novel TSNAX/DISC1 fusion protein. ${ }^{49}$

Association between polymorphisms in TSNAX/DISC1 and the risk of developing SCZ and BPAD in the Southern Indian population has not been evaluated before, and the present study was conducted to detect the associations reported in other populations. A case-control design was used in order to test the association of SNPs between cohorts of SCZ cases, BPAD cases, cases with a combined phenotype (SCZ or BPAD) and healthy controls. As there were previous reports ${ }^{13,15,27}$ of sex-specific associations, we also analysed the data based on the gender.

\section{MATERIALS AND METHODS}

\section{Subjects}

All individuals included in this study were unrelated and of Southern Indian ethnic origin. The study sample comprised of 419 patients with diagnosis of BPAD type I (225 males and 194 females; mean age at assessment: 29.02 \pm 10.98 years, mean age at onset: $20.73 \pm 6.96$ years) and 408 patients with diagnosis of SCZ (246 males and 162 females; mean age at assessment: 29.08 \pm 7.84 years, mean age at onset: $23.21 \pm 7.16$ years) recruited from the inpatient and outpatient services of National Institute of Mental Health and Neuro Sciences (NIMHANS), Bangalore, India. All patients were evaluated using the Diagnostic Interview for Genetic Studies. ${ }^{50}$ Patients were diagnosed by at least two experienced Psychiatrists using Diagnostic and Statistical Manual of Mental Disorders-IV (DSM-IV) criteria. $^{51}$ Control subjects $(N=425 ; 243$ males and 182 females mean age: $33.61 \pm 11.15$ years $)$ were recruited by a standardized semi-structured interview with psychiatrists from healthy volunteers and hospital staff who had no family history of axis I disorders, in first degree relatives. ${ }^{52}$ Cases and controls were statistically matched for gender (Supplementary Table 1).

The study was approved by the Institute ethics committee. All participants gave written informed consent after a complete description of the study.

\section{SNP Selection and Genotyping}

Seven SNPs spanning 492 kilo bases from intron 4 of the TSNAX to the $3^{\prime}$-untranslated region of the DISC1, which have shown significant association with SCZ and/or BPAD in other populations, were selected for the study (Figure 1). In all, $10 \mathrm{ml}$ of venous blood was collected from the participating subjects and genomic DNA was isolated using modified salting-out method. ${ }^{53}$ The SNPs were genotyped in two sets using the ABI PRISM SNaPshot Multiplex Kit (Applied Biosystems, Foster City, CA, USA). PCR was carried out using an ABI 9700 (Applied Biosystems)/eppendorf thermocycler (Eppendorf Scientific, Inc., Westbury, NY, USA). Template preparation after PCR was performed using shrimp alkaline phosphatase and exonuclease I and post-extension treatment was done using shrimp alkaline phosphatase. SNaPshot products were analysed using an ABI PRISM 377 DNA Sequencer
(Applied Biosystems). Genotypes were determined using Gene Scan $v 3.1$ and Genotyper $v 2.1$ software (Applied Biosystems). Allele scoring was performed blind to diagnosis, and two raters confirmed the scoring. The genotyping call rate was $97.8 \%$. Conflicts in allele scoring were resolved by individual SNP genotyping.

As genetic case-control studies are known to be susceptible to population stratification, we genotyped six unlinked Alu polymorphisms in 100 individuals from each category $(N=300)$ to assess the genetic homogeneity of our samples. $A l u$ repeats are a family of short interspersed elements and are predominantly present in the non-coding regions of the primate genome. Alu repeats have no known biological function ${ }^{54}$ and have been used to study the history of substitution patterns in the human genome. ${ }^{55}$ Polymorphic Alu insertions have been used as markers to determine genetic distances between human subpopulations. ${ }^{56}$ We did not observe any difference in the allelic or genotypic distribution between the samples, or between the sexes (Supplementary Table 2).

\section{Statistical analysis}

Mann-Whitney test was performed to check for age differences between cases and controls. The difference in age between cases and controls was found to be statistically significant. Binary logistic regression analysis (SPSS version 15, SPSS Inc., Chicago, IL, USA) was done with genotypes recoded into the number of alleles ( 0,1 and 2, with 1 being the heterozygote) and recoded genders ( 1 and 2, 1 being male) considering age as a covariate. Allele and genotype frequencies were also compared using standard Chi-square $\left(\chi^{2}\right)$ tests. Haplotype analysis was performed using HAPLOVIEW v 4.0 (Broad Institute, Cambridge, MA, USA), which uses the expectation maximization algorithm ${ }^{57}$ to estimate haplotype frequencies. Hardy-Weinberg equilibrium was assessed for all markers using HAPLOVIEW v 4.0. In accordance with the common variant common disease hypothesis for complex disorders, rs6675281 and rs 11122396 were excluded from further analysis as the minor allele frequencies were found to be $<5 \%$ in controls. The frequency of rs 11122396 has been seen to be quite low (2\%) also in Caucasians ${ }^{15}$ and that of rs6675281 was higher (12 to $14 \%$ ) in Caucasians and Asian studies compared with our study. ${ }^{14,15,20,24,58}$ rs1615409 was also excluded from the analysis as it was in strong linkage disequilibrium with rs766288 (controls- $D^{\prime}=0.95, r^{2}=0.606$; SCZ- $D^{\prime}=0.962$, $r^{2}=0.562$ and BPAD- $D^{\prime}=0.969, r^{2}=0.566$ ). The linkage disequilibrium structure for the four SNPs studied is given in Supplementary Figure 1. Association tests with $p$-values $<0.05$ were considered to be nominally significant. We corrected for multiple tests using false discovery rate (FDR) approach. ${ }^{59}$ We used an overall FDR of 0.05 for our association tests. As we performed tests for four SNPs, we used the FDR correction for four tests for the single-marker analyses. The corrections were done within each gender and phenotype separately. For two loci analysis, a combination of 'allele 1' in rs766288 and 'allele 2' in rs2812393 was considered the risk haplotype for regression analysis. The number of copies of the risk alleles was coded as 0,1 or 2. For example for $\mathrm{C}-\mathrm{C}$ risk combination, $\mathrm{C} / \mathrm{C}-\mathrm{C} / \mathrm{C}$ coded as $2, \mathrm{C} / \mathrm{C}-\mathrm{C} / \mathrm{G}$ or $\mathrm{C} / \mathrm{A}-\mathrm{C} / \mathrm{G}$ or $\mathrm{C} / \mathrm{A}-\mathrm{C} / \mathrm{C}$ coded as 1 and $\mathrm{C} / \mathrm{C}-\mathrm{G} / \mathrm{G}, \mathrm{C} / \mathrm{A}-\mathrm{G} / \mathrm{G}, \mathrm{A} / \mathrm{A}-\mathrm{G} / \mathrm{G}, \mathrm{A} / \mathrm{A}-\mathrm{C} /$ $\mathrm{C}$ and $\mathrm{A} / \mathrm{A}-\mathrm{C} / \mathrm{G}$ coded as 0 . As there were four allelic combinations in each of the two-locus analysis, the FDR corrections were implemented for four tests The corrections were done within each gender and phenotype separately. Power calculations were performed by using QUANTO 1.2 software (http:// hydra.usc.edu/gxe). The power of our study sample was calculated based on the observed range of allele frequencies, the odds ratio of 1.2 , prevalence of $1 \%$, a 1:1.041 case-control ratio for BPAD and a 1:1.014 case-control ratio for SCZ under a $\log$ additive genetic model at the 0.05 significance.

\section{RESULTS}

\section{Single-Marker analysis}

SNP frequencies for cases and control groups did not deviate significantly from the Hardy-Weinberg equilibrium cutoff $(P<0.001)$. One SNP (rs821616) showed moderate significant association $(P<0.05)$ with cases compared with controls in regression analysis (Table 1). Associations were found to be significant with BPAD phenotype $(P=0.035)$ and combined phenotype of BPAD or SCZ $(P=0.04)$. However, the results did not retain statistical 


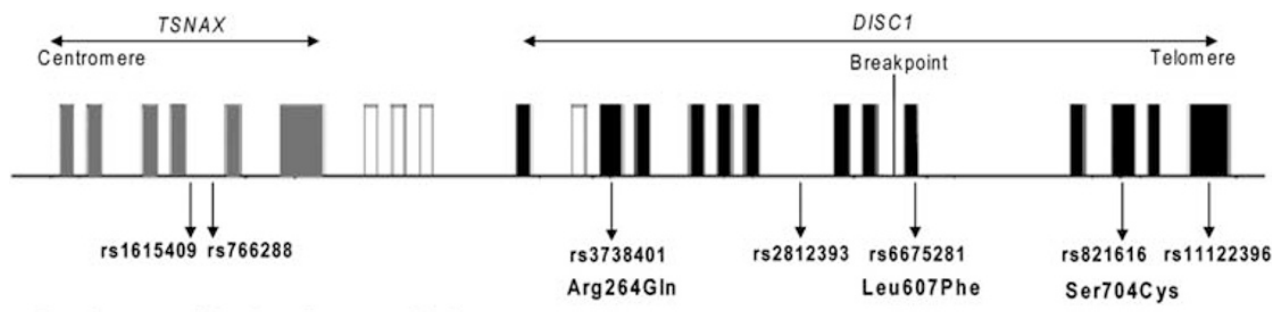

Previous studies in otherpopulations:

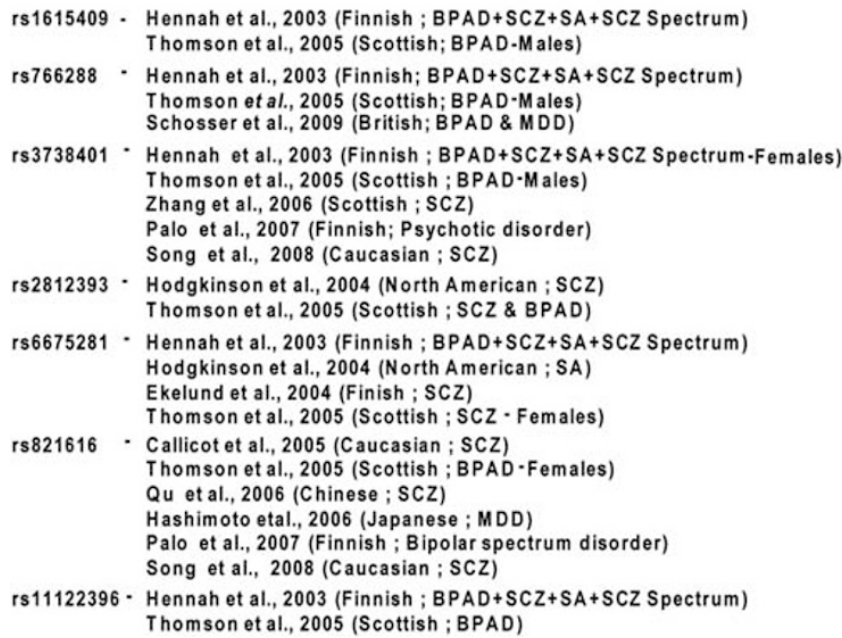

\section{Inter.marker distance}

rs1615409-rs766288 (10.2 Kb) rs766288 - rs3738401 (136.6 Kb) rs3738401.rs2812393 (83.3 Kb) (s2812393 - rs675281 (40.4K (b) (190.4 K b) s6675281-rs821616 (190.4 Kb) rs821616 - rs11122396 (30.6 Kb)

Figure 1 Schematic diagram of exons of TSNAX (grey boxes), the disrupted in Schizophrenia 1 (DISC1) (black boxes), and the intergenic exons (white boxes). The seven SNPs studied are shown in the context of the exonic structure of these genes. The positive reports are shown with inter-marker distance. The figure is adapted from Hennah et al. 2003.

Table 1 Logistic regression analysis-genotype + age as covariate

\begin{tabular}{|c|c|c|c|c|c|c|c|}
\hline & \multicolumn{3}{|c|}{$\mathrm{P}$-value ${ }^{a}$ /beta value } & \multicolumn{4}{|c|}{ HWE P-value } \\
\hline & $B P A D$ & $S C Z$ & $B P A D+S C Z$ & Controls & $B P A D$ & $S C Z$ & $B P A D+S C Z$ \\
\hline \multicolumn{8}{|l|}{ rs766288 } \\
\hline Gender combined & $0.074 /-0.192$ & $0.906 /-0.013$ & $0.336 /-0.090$ & 0.1854 & 0.1396 & 0.1792 & 0.0399 \\
\hline Females & $0.004^{b} /-0.483$ & $0.03 /-0.368$ & $0.004^{b} /-0.417$ & 0.8972 & 0.3421 & 1 & 0.5645 \\
\hline Males & $0.0902 / 0.018$ & $0.105 / 0.230$ & $0.248 / 0.146$ & 0.043 & 0.2669 & 0.05 & 0.0219 \\
\hline \multicolumn{8}{|l|}{ rs3738401 } \\
\hline Gender combined & $0.368 / 0.102$ & $0.794 /-0.030$ & $0.520 / 0.065$ & 0.0053 & 0.7792 & 0.9957 & 0.9283 \\
\hline Females & $0.443 / 0.133$ & $0.473 /-0.137$ & $0.875 / 0.025$ & 0.3667 & 0.9978 & 0.7332 & 0.9719 \\
\hline Males & $0.0614 / 0.076$ & $0.427 / 0.199$ & $0.529 / 0.083$ & 0.0058 & 0.8037 & 0.9973 & 0.7927 \\
\hline \multicolumn{8}{|l|}{$r s 821616$} \\
\hline Gender combined & $0.035 /-0.605$ & $0.179 /-0.367$ & $0.04 /-0.480$ & 0.3521 & 0.678 & 0.2184 & 0.6552 \\
\hline Females & $0.175 /-0.537$ & $0.213 /-0.522$ & $0.138 /-0.506$ & 0.4544 & 0.9219 & 0.5994 & 0.5954 \\
\hline Males & $0.112 /-0.670$ & $0.579 /-0.203$ & $0.183 /-0.429$ & 0.302 & 0.4083 & 0.398 & 0.9786 \\
\hline
\end{tabular}

Abbreviations: BPAD, bipolar affective disorder; HWE, Hardy-Weinberg equilibrium; SCZ, schizophrenia.

Genotypes recoded into the number of alleles ( 0,1 and 2 , with 1 being the heterozygote) and recoded genders ( 1 and 2,1 being male). $P$ value $<0.05$ and their corresponding beta values are shown in bold.

auncorrected $P$-value.

bSignificant after false discovery rate corrections $(n=4)$. 
Table 2 Results from association analysis for four-marker haplotypes in TSNAX/DISC1

\begin{tabular}{|c|c|c|c|c|}
\hline \multirow[b]{2}{*}{ Haplotype } & \multicolumn{2}{|c|}{ Frequency } & \multirow[b]{2}{*}{ P-value ${ }^{a}$} & \multirow[b]{2}{*}{ Phenotype } \\
\hline & Cases & Controls & & \\
\hline CGGT & 0.049 & 0.074 & 0.028 & BPAD \\
\hline CGGT & 0.05 & 0.078 & 0.0189 & SCZ \\
\hline CGGT & 0.048 & 0.074 & 0.0065 & $\mathrm{BPAD}+\mathrm{SCZ}$ \\
\hline AGGT & 0.024 & 0.038 & 0.0469 & $\mathrm{BPAD}+\mathrm{SCZ}$ \\
\hline AGGT & 0.023 & 0.053 & 0.0273 & BPAD females \\
\hline AGGT & 0.024 & 0.05 & 0.0209 & BPAD females + SCZ females \\
\hline CGGT & 0.054 & 0.086 & 0.0205 & BPAD males + SCZ males \\
\hline
\end{tabular}

Abbreviations: BPAD, bipolar affective disorder; DISC1, disrupted in Schizophrenia 1; SCZ, schizophrenia.

aUncorrected $P$-values; results of $P<0.05$ are shown.

significance after multiple corrections at level $0.05(n=4)$. As there were reports of gender-specific effects we analysed the samples stratified by gender and significant association was found at rs766288 and rs2812393 for females (Table 1). The most significant association was found for rs766288 with BPAD females $(P=0.004)$ and combined female cases of BPAD or SCZ $(P=0.004)$, which withstood FDR corrections $(n=4)$. Moderate associations were also observed in females for rs766288 (SCZ, $P=0.03$ ) and rs2812393 (SCZ, $P=0.026$; BPAD + SCZ, $P=0.028$ ). Binary logistic regression analysis for the combined sample comprising both males and females at rs766288 did not show any statistical significance after adjusting for gender (Supplementary Table 3 ). This could be due to the difference in allele frequencies in males (0.319) and females (0.371) at rs766288. However, there was significant evidence of genotype-gender interaction (Supplementary Table 4). Results of $\chi^{2}$ tests and odds ratio is shown in Supplementary Table 5 and Supplementary Table 6.

\section{Haplotype analysis}

The haplotype tests of association were performed with all fourmarker haplotypes. Haplotypes with estimated frequencies of $>1 \%$ in both cases and controls were considered for analysis. Results of haplotype analysis with $P<0.05$ is shown in Table 2. C-G-G-T haplotype showed relatively lesser frequency in $\operatorname{BPAD}(P=0.028)$, SCZ $(P=0.0189)$ and combined cases of BPAD or SCZ $(P=0.0065)$ and combined males of BPAD or SCZ $(P=0.0205)$ compared with controls. Haplotype A-G-G-T was also underrepresented in combined cases of BPAD or SCZ $(P=0.0469)$, BPAD females $(P=0.0273)$ and pooled females of BPAD or SCZ $(P=0.0209)$. The nominal associations found did not remain significant after multiple corrections at level 0.05 .

\section{Two-locus analysis}

Two-locus analyses were performed using binary logistic regression for the three SNPs in combinations of rs766288-rs2812393, rs766288rs821616 and rs2812393-rs821616 as we found nominal associations for these loci.

\section{rs766288-rs2812393}

Analyses of these two SNPs showed significant associations with allelic combination $\mathrm{C}-\mathrm{C}(P=0.009)$ in the BPAD phenotype when multiple corrections were performed for all tests within each stratified gender (combined, females, males). The regression coefficient for the $\mathrm{C}-\mathrm{C}$ combination was positive indicating that this allelic combination increases the risk in BPAD. Female-specific combinations were also
Table 3 Two locus analysis of rs766288 and rs2812393

\begin{tabular}{|c|c|c|}
\hline rs766288 & rs2812393 & P-valuea/beta value \\
\hline \multicolumn{3}{|l|}{$B P A D(\mathrm{~N}=419)$} \\
\hline$C$ & C & $0.009 / 0.295$ \\
\hline A & G & $0.412 /-0.111$ \\
\hline c & G & 0.979/0.003 \\
\hline A & c & $0.879 /-0.038$ \\
\hline \multicolumn{3}{|l|}{$S C Z(N=408)$} \\
\hline C & C & $0.099 / 0.184$ \\
\hline A & G & $0.62 /-0.068$ \\
\hline c & G & $0.46 /-0.088$ \\
\hline A & C & $0.529 / 0.08$ \\
\hline \multicolumn{3}{|l|}{ Combined cases $(\mathrm{N}=827)$} \\
\hline $\mathrm{C}$ & C & $0.016 / 0.236$ \\
\hline A & G & $0.551 /-0.07$ \\
\hline C & G & $0.703 /-0.039$ \\
\hline A & C & $0.632 / 0.053$ \\
\hline
\end{tabular}

BPAD females $(\mathrm{N}=194)$

$\begin{array}{lll}\text { C } & \text { C } & 0.003 / 0.522 \\ \text { A } & \text { G } & 0.598 / 0.096 \\ \text { C } & \text { G } & 0.717 / 0.064 \\ \text { A } & \text { C } & 0.161 /-0.276\end{array}$

SCZ females $(\mathrm{N}=162)$

$\begin{array}{lll}\text { C } & \text { C } & 0.011 / 0.46 \\ \text { A } & \text { G } & 0.016 /-0.526 \\ \text { C } & \text { G } & 0.626 /-0.09 \\ \text { A } & \text { C } & 0.423 /-0.163\end{array}$

Combined female cases $(\mathrm{N}=356)$

$\begin{array}{lll}C & C & 0.001 / 0.495 \\ A & G & 0.013 /-0.488 \\ C & G & 0.969 /-0.006 \\ A & \text { C } & 0.216 /-0.212\end{array}$

$\begin{array}{rll}\text { BPAD males }(\mathrm{N}=225) & & \\ \text { C } & \text { C } & 0.414 / 0.122 \\ \text { A } & \text { G } & 0.057 /-0.389 \\ \text { C } & \text { G } & 0.764 /-0.047 \\ \text { A } & \text { C } & 0.299 / 0.175\end{array}$

\begin{tabular}{cll} 
SCZ males $(\mathrm{N}=246)$ & & \\
C & C & $0.993 /-0.001$ \\
A & G & $0.174 / 0.245$ \\
C & G & $0.639 /-0.074$ \\
A & C & $0.175 / 0.222$ \\
\hline Combined male cases $(N=471)$ & & \\
C & C & $0.703 / 0.049$ \\
A & G & $0.212 / 0.197$ \\
C & G & $0.672 /-0.058$ \\
A & C & $0.099 / 0.241$
\end{tabular}

Abbreviations: BPAD, bipolar affective disorder; SCZ, schizophrenia. $P$ value $<0.05$ and their corresponding beta values are shown in bold. aUncorrected $P$-values; $N$-number of samples. 
observed (Table 3). Other combinations in BPAD females $(\mathrm{C}-\mathrm{C}$, $P=0.003$, risk combination) and SCZ females (C-C, $P=0.011$, risk combination; A-G, $P=0.016$, protective combination), combined female cases (A-G, $P=0.013$, protective combination; C-C, $P=0.001$, risk combination) were found to be significantly associated after FDR corrections $(n=12)$. If FDR corrections are performed only within a phenotype and gender-based analysis $(n=4)$, we also obtained significance with $\mathrm{C}-\mathrm{C}$ combination $(P=0.016$, risk combination) in BPAD cases.

\section{rs766288-rs821616}

Allelic combination C-A $(P=0.004)$ in the female cases with combined phenotype showed significant association when multiple corrections were performed for all tests within each stratified gender (combined, females, males). A positive regression coefficient value for the C-A combination was suggestive that female cases with this allelic combination are at increased risk. Few additional combinations that were found to be significantly associated after multiple corrections $(n=12)$ were $\mathrm{A}-\mathrm{T}$ in $\mathrm{BPAD}$ females $(P=0.012$, protective combination); $\mathrm{C}-\mathrm{A}(P=0.014$, risk combination), $\mathrm{C}-\mathrm{A}$ in SCZ females $(P=0.011$, risk combination), $\mathrm{A}-\mathrm{T}$ in combined female cases $(P=0.012$, protective combination) and $\mathrm{A}-\mathrm{A}$ in combined female cases $(P=0.022$, protective combination) compared with control females (Table 4). If FDR corrections are performed only within a phenotype and gender-based analysis $(n=4)$, we also obtained significance with A-A $(P=0.032$, protective combination) in BPAD females. However nominal significance observed in BPAD $(\mathrm{C}-\mathrm{A}$, $P=0.024$, risk combination), cases with the combined phenotype (C$\mathrm{A}, P=0.019$, risk combination), SCZ males (A-A, $P=0.016$, risk combination) and males with the combined phenotype (A-A, $P=0.028$, risk combination), which did not withstand the multiple corrections.

\section{rs2812393-rs821616}

Allelic combinations of G-T in SCZ $(P=0)$, combined cases of BPAD or SCZ $(P=0.001)$, SCZ females $(P=0.007)$ and combined females $(P=0.005)$ were observed to be protective combination of alleles (Table 5). These combinations survived multiple corrections $(n=12)$. In addition allelic combinations of G-T (BPAD, $P=0.017$; BPAD females, $P=0.035$; SCZ males, $P=0.02$; combined males, $P=0.039$ ) showed nominal significance, but did not withstand FDR corrections $(n=4)$.

\section{DISCUSSION}

In the present study, we observed nominal significance in the entire sample set for a non-synonymous SNP rs821616 (Ser704Cys) with BPAD and a combined phenotype of BPAD or SCZ. However these results did not withstand multiple corrections.

At the SNP rs766288, gender-specific association was observed which remained significant after multiple corrections. Female-specific associations in DISC1 have been reported earlier for SCZ at rs2295959 in Han Chinese ${ }^{27}$ and rs821616 in a Japanese population. ${ }^{60}$ An early study on a Finnish cohort with a broad phenotype, which included SCZ, schizoaffective disorder, SCZ spectrum diagnosis and BPAD, reported the under-transmission of a haplotype that comprised of rs751229 and rs3738401 at the $5^{\prime}$ end of DISC1 to affected females. ${ }^{13}$ HEP2 (rs1615344-rs1615409-rs766288) (C-A-C) also showed significance in combined samples of males and females and also under-transmitted when samples were stratified by gender. Interestingly rs766288 showed significance in an 8-SNP haplotype in the TSNAX/DISC1 region of G-C-C-G-A-C-A-G (rs1630250-
Table 4 Two locus analysis of rs766288 and rs821616

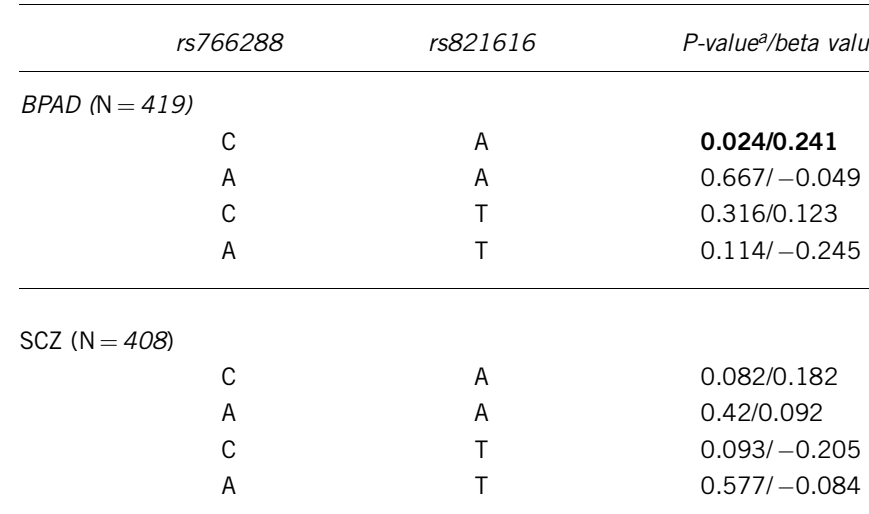

Combined cases $(\mathrm{N}=827)$

$\begin{array}{lll}\text { C } & \text { A } & 0.019 / 0.217 \\ \text { A } & \text { A } & 0.831 / 0.201 \\ \text { C } & \text { T } & 0.115 / 0.167 \\ \text { A } & \text { T } & 0.215 /-0.162\end{array}$

BPAD females $(\mathrm{N}=194)$

$\begin{array}{lll}\mathrm{C} & \mathrm{A} & 0.014 / 0.4 \\ \mathrm{~A} & \mathrm{~A} & 0.032 /-0.38 \\ \mathrm{C} & \mathrm{T} & 0.835 /-0.038 \\ \mathrm{~A} & \mathrm{~T} & 0.012 /-0.589\end{array}$

SCZ females $(\mathrm{N}=162)$

$\begin{array}{lll}\text { C } & \text { A } & 0.011 / 0.421 \\ \text { A } & \text { A } & 0.074 /-0.331 \\ \text { C } & \text { T } & 0.307 /-0.197 \\ \text { A } & \text { T } & 0.097 /-0.391\end{array}$

Combined female cases $(\mathrm{N}=356)$

$\begin{array}{lll}\mathrm{C} & \mathrm{A} & 0.004 / 0.412 \\ \mathrm{~A} & \mathrm{~A} & 0.022 /-0.351 \\ \mathrm{C} & \mathrm{T} & 0.489 /-0.113 \\ \mathrm{~A} & \mathrm{~T} & 0.012 /-0.497\end{array}$

BPAD males $(\mathrm{N}=225)$

$\begin{array}{lll}\text { C } & \text { A } & 0.413 / 0.177 \\ \text { A } & \text { A } & 0.187 / 0.199 \\ \text { C } & \text { T } & 0.244 /-0.192 \\ \text { A } & \text { T } & 0.875 / 0.033\end{array}$

SCZ males $(\mathrm{N}=246)$

$\begin{array}{lll}\text { C } & \text { A } & 0.901 / 0.017 \\ \text { A } & \text { A } & 0.016 / 0.357 \\ \text { C } & \text { T } & 0.177 /-0.212 \\ \text { A } & \text { T } & 0.476 / 0.141\end{array}$

Combined male cases $(\mathrm{N}=471)$

$\begin{array}{lll}\text { C } & \text { A } & 0.589 / 0.067 \\ \text { A } & \text { A } & 0.028 / 0.290 \\ \text { C } & \text { T } & 0.138 /-0.206 \\ \text { A } & \text { T } & 0.606 / 0.091\end{array}$

Abbreviations: BPAD, bipolar affective disorder; SCZ, schizophrenia. $P$ value $<0.05$ and their corresponding beta values are shown in bold aUncorrected $P$-values; $N$-number of samples. 
Table 5 Two locus analysis of rs2812393 and rs821616

\begin{tabular}{cccl}
\hline \multicolumn{1}{c}{ rs2812393 } & rs821616 & P-valuea/beta value \\
\hline BPAD $(\mathrm{N}=419)$ & & & \\
& $\mathrm{C}$ & $\mathrm{A}$ & $0.088 / 0.188$ \\
& $\mathrm{G}$ & $\mathrm{A}$ & $0.699 / 0.045$ \\
& $\mathrm{G}$ & $\mathrm{T}$ & $0.017 /-0.334$ \\
& $\mathrm{C}$ & $\mathrm{T}$ & $0.799 /-0.035$ \\
\hline $\mathrm{SCZ}(\mathrm{N}=108)$ & & & \\
& $\mathrm{C}$ & $\mathrm{A}$ & \\
& $\mathrm{G}$ & $\mathrm{A}$ & $0.236 / 0.138$ \\
& $\mathrm{G}$ & $\mathrm{T}$ & $0.974 /-0.004$ \\
& $\mathrm{C}$ & $\mathrm{T}$ & $0 /-0.521$ \\
& & & $0.381 /-0.199$ \\
\hline
\end{tabular}

Combined cases $(\mathrm{N}=827)$

$\begin{array}{lll}C & A & 0.125 / 0.146 \\ G & A & 0.806 / 0.025 \\ G & T & \mathbf{0 . 0 0 1 / - 0 . 4 1 6} \\ C & T & 0.531 /-0.073\end{array}$

BPAD females $(\mathrm{N}=194)$

$\begin{array}{lll}C & A & 0.172 / 0.228 \\ G & \text { A } & 0.729 / 0.061 \\ G & \text { T } & 0.035 /-0.439 \\ C & T & 0.752 / 0.063\end{array}$

SCZ females $(\mathrm{N}=162)$

$\begin{array}{lll}C & A & 0.078 / 0.306 \\ G & A & 0.958 / 0.01 \\ G & T & 0.007 /-0.621 \\ C & T & 0.659 / 0.09\end{array}$

Combined female cases $(\mathrm{N}=356)$

$\begin{array}{lll}C & A & 0.077 / 0.265 \\ G & A & 0.834 / 0.033 \\ G & T & 0.005 /-0.52 \\ C & T & 0.642 / 0.081\end{array}$

BPAD males $(\mathrm{N}=225)$

$\begin{array}{lll}C & A & 0.268 / 0.164 \\ G & A & 0.859 / 0.027 \\ G & T & 0.193 /-0.246 \\ C & T & 0.537 /-0.115\end{array}$

SCZ males $(N=246)$

$\begin{array}{lll}C & A & 0.931 /-0.012 \\ G & A & 0.941 /-0.011 \\ G & T & \mathbf{0 . 0 2 / - 0 . 4 5 1} \\ C & \text { T } & 0.119 /-0.284\end{array}$

Combined male cases $(\mathrm{N}=471)$

$\begin{array}{lll}C & A & 0.673 / 0.053 \\ G & A & 0.898 / 0.017 \\ G & T & 0.039 /-0.336 \\ C & T & 0.206 /-0.2\end{array}$

Abbreviations: BPAD, bipolar affective disorder; SCZ, schizophrenia. $P$ value $<0.05$ and their corresponding beta values are shown in bold. aUncorrected $P$-values; $N$-number of samples. rs1615409-rs766288-rs1025526-rs1030711-rs751229-rs1285730rs3738401) with BPAD males, in the Scottish population. ${ }^{15}$ In our study the $\mathrm{C}$ allele of rs766288 was overrepresented in BPAD females (72.9\%), SCZ females (71\%) and combined females of BPAD or SCZ (72.1\%) as compared with female controls (62.9\%). Further in our study C-A (rs766288-rs821616), A-A and A-T allelic combinations showed association with female cases. C-A seems to be a risk combination while A-A and A-T are likely to be protective. The two other two-locus analysis involving rs766288 also showed $\mathrm{C}$ as risk haplotype. C-C (rs766288-rs2812393) allelic combination seemed to be risk factor in BPAD, which was severe in females. Our results for rs766288 are in concordance with the previous reports and suggest that $\mathrm{C}$ might be the risk allele.

We also observed nominal associations for rs2812393. Two-locus analysis of rs2812393-rs821616 showed G-T as protective combination of alleles in gender combined samples of SCZ, BPAD or SCZ, as well as in females. C-C (rs766288-rs2812393) appeared to be a risk combination. Thomson et al. ${ }^{15}$ have reported an overrepresentation of $\mathrm{G}$ allele of rs2812393 in a three marker haplotype C-G-T (rs2492367-rs2812393-rs1322784) in BPAD and also in BPAD female subjects from Scotland. rs766288 and rs2812393 lie in intron 4 of TSNAX and intron 6 of DISC1 gene. As TSNAX and DISC1 are known to form fusion transcripts, these SNPs could be involved in the formation of isoforms via alternative splicing or could be associated with some other functional variant in the region. The mechanism of sex-specific effects of these genes could be through variation in hormone responsive promoter or enhancer sequences, affecting either TSNAX/DISC1 or other genes that interact with them.

Our results for Ser704Cys polymorphism in the complete sample set is in accordance with the report in a Caucasian sample with allele A overtransmission (71\%) for SCZ. ${ }^{16}$ We also observed a relative excess of the A allele (Ser704) in cases $(77.2 \%$ SCZ, $76.5 \%$ BPAD, $76.84 \%$ combined cases) compared with controls (72.2\%). Discordant findings have been observed for this polymorphism with an excess of $\mathrm{T}$ allele in SCZ in a Chinese sample set $(15.7 \% \text { in cases and } 10.4 \% \text { in controls })^{28}$ and in another Caucasian sample (33\% for cases and $27 \%$ for controls). ${ }^{20}$ These differences suggest that there could be allelic heterogeneity associated with the polymorphism. This SNP is in exon 11 of DISC1, an exon known to undergo alternative splicing and encodes a region of the protein thought to be involved in interactions with ATF4, ATF5, LIS1, GRB2 and NDEL1. ${ }^{45}$ The Ser allele has been shown to be associated with structural and functional changes in the hippocampus including reduction in grey matter volume in Caucasian data set. ${ }^{16}$ Ser704 homozygotes have shown greater pre-frontal activation, with significant differences in the left middle and inferior frontal gyri, and in the right inferior frontal gyrus, which could be interpreted as a manifestation of less efficient pre-frontal function, with more activation required to achieve the same behavioural output. ${ }^{61}$ Ser704Cys polymorphism is also shown to be associated with altered expression of transcripts lacking exon 3 and, exon 7 and $8 .^{62}$ The short transcripts were found to be highly expressed in the brains of patients with SCZ than in control brains, and were associated with genetic variations in the DISC1 gene. Power analysis showed our sample set had power of $42.4 \%$ for BPAD and $42.6 \%$ SCZ for rs766288, 45.5\% for BPAD, 44.1\% for SCZ for rs 2812393 and 40.5 and $35.4 \%$ for SCZ for rs 821616 with an odds ratio of 1.2 . These nominal associations observed in our sample could be a false positive finding due to inadequate statistical power. The possibility of involvement of Ser704Cys polymorphism in the susceptibility of psychosis still remains unclear. 
The associations we have identified are unlikely to have arisen as a result of population stratification within our samples-firstly the allele frequencies of the analysed SNPs other than rs6675281 are congruent with the reported allele frequencies in Caucasian populations and secondly, the Alu markers did not show significant differences in the groups studied (Supplementary Table 2). However, these data should be interpreted with caution as there are chances of type I error. $^{63}$

We could not replicate the association for the other SNP studied rs3738401 with SCZ or BPAD that have been reported previously in other ethnic groups. The difference in the ethnic background of the subjects, and the study design viz sample size, sampling bias, family vs population based, and so on between studies may account for inconsistent results. These reported SNPs might not be causative, and could be in linkage disequilibrium with some other disease predisposing allele within the gene or near the gene. The SNPs studied could be associated with SCZ or BPAD in a haplotype with other polymorphisms or could be a susceptibility allele only in subgroup of the phenotype. It is evident that most of the positive studies in this region have been from Caucasian populations, while findings in the Asian population have been mixed, with largely negative reports. ${ }^{37-39}$ This could be explained by the differences in the linkage disequilibrium pattern and differences in allele frequencies across populations. Alternatively, in complex diseases such as SCZ and $\mathrm{BPAD}$, in which multiple loci act jointly to confer susceptibility for disease, associations of different alleles at the same locus could be attributed to a correlation with a causal polymorphism at another locus. ${ }^{64}$ However our results for rs766288, rs2812393 and rs821616 are suggestive of the involvement of this locus in susceptibility to BPAD and SCZ.

The present study has some limitations. Firstly, the number of SNPs studied might not represent the entire region, as TSNAX/DISC1 region comprises $\sim 610 \mathrm{~kb}$. Thus, we cannot exclude the possibility of other SNPs in the region being involved in conferring risk for BPAD and SCZ. Second, the sample size for the current analyses was relatively modest, with further reduction for gender-based comparisons, and further replication is necessary.

However, it should also be noted that the multiple corrections applied here are very conservative taking into account our study design has a directional hypothesis based on previous findings. Despite the limitations, we believe our study contributes to greater insight into the TSNAX/DISC1 locus association with psychosis. In an era where genome-wide association study have rapidly become a standard method for disease gene discovery, there is still a need for focused candidate gene association studies in different populations, as most genome-wide association study have been with European sample sets, and limited reports are available from Asian populations, ${ }^{65-67}$ as there are likely to be population-specific variants. ${ }^{68}$

In conclusion, we find significant gender-specific associations with two intronic SNPs in TSNAX and DISC1, and an exonic SNP from DISC1. Further replication, in larger and more diverse samples, using dense markers, may be necessary to understand the role of these genes in the pathophysiology of these disorders.

\section{ACKNOWLEDGEMENTS}

We thank all the participants for participation in the study. We also thank Mr. J Muralidharan for his technical assistance and thank Indian Council of Medical Research (ICMR) and Council of Scientific and Industrial Research (CSIR) for their financial support. These councils played no part in the study design, its execution or the decision to submit the paper for publication.
1 Nurnberger, Jr J.I. \& Berrettini, W. Psychiatric Genetics (Chapman and Hall, London, 1988).

2 Shih, R.A., Belmonte, P.L. \& Zandi, P.P. A review of the evidence from family, twin and adoption studies for a genetic contribution to adult psychiatric disorders. Int. Rev. Psychiatry 16, 260-283 (2004).

3 St Clair, D., Blackwood, D., Muir, W., Carothers, A., Walker, M., Spowart, G. et al. Association within a family of a balanced autosomal translocation with major mental illness. Lancet 336, 13-16 (1996).

4 Millar, J.K., Wilson-Annan, J.C., Anderson, S., Christie, S., Taylor, M.S., Semple, C.A. et al. Disruption of two novel genes by a translocation co-segregating with schizophrenia. Hum. Mol. Genet. 9, 1415-1423 (2000).

5 Blackwood, D.H., Fordyce, A., St Walker, M.T., Clair, D.M., Porteous., D.J. \& Muir, W.J. Schizophrenia and affective disorders-cosegregation with a translocation at chromosome 1q42 that directly disrupts brain-expressed genes: clinical and P300 findings in a family. Am. J. Hum. Genet. 69, 428-433 (2001).

6 Hovatta, I., Varilo, T., Suvisaari, J., Terwilliger, J.D., Ollikainen, V., Arajarvi, R. et al. A genomewide screen for schizophrenia genes in an isolated Finnish subpopulation, suggesting multiple susceptibility loci. Am. J. Hum. Genet. 65, 1114-1124 (1999).

7 Ekelund, J., Hovatt, I., Parker, A., Paunio, T., Varilo, T., Martin, R. et al. Chromosome 1 loci in Finnish schizophrenia families. Hum. Mol. Genet. 10, 1611-1617 (2001).

8 Ekelund, J., Hennah, W., Hiekkalinna, T., Parker, A., Meyer, J., Lonnqvist, J. et al. Replication of $1 \mathrm{q} 42$ linkage in Finnish schizophrenia pedigrees. Mol. Psychiatry 9, 1037-1041 (2004).

9 Hwu, H.G., Liu, C.M., Fann, C.S., Ou-Yang, W.C. \& Lee, S.F. Linkage of schizophrenia with chromosome 1q loci in Taiwanese families. Mol. Psychiatry 8, 445-452 (2003).

10 Detera-Wadleigh, S.D., Badner, J.A., Berrettini, W.H., Yoshikawa, T., Goldin, L.R., Turner, G. et al. A high-density genome scan detects evidence for a bipolar-disorder susceptibility locus on $13 q 32$ and other potential loci on $1 q 32$ and 18p11.2. Proc. Natl Acad. Sci. USA 96, 5604-5609 (1999).

11 Curtis, D., Kalsi, G., Bryniolfsson, J., McInnis, M., O'Neill, J., Smyth, C. et al. Genome scan of pedigrees multiply affected with bipolar disorder provides further support for the presence of a susceptibility locus on chromosome 12q23-q24, and suggests the presence of additional loci on 1p and 1q. Psychiatry Genet. 13, 77-84 (2003).

12 Macgregor, S., Visscher, P.M., Knott, S.A., Thomson, P., Porteous, D.J., Millar, J.K. et al. A genome scan and follow-up study identify a bipolar disorder susceptibility locus on chromosome 1q42. Mol. Psychiatry 9, 1083-1090 (2004).

13 Hennah, W., Varilo, T., Kestila, M., Paunio, T., Arajarvi, R., Haukka, J. et al. Haplotype transmission analysis provides evidence of association for DISC1 to schizophrenia and suggests sex-dependent effects. Hum. Mol. Genet. 12, 3151-3159 (2003).

14 Hodgkinson, C.A., Goldman, D., Jaeger, J., Persaud, S., Kane, J.M., Lipsky, R.H. et al. Disrupted in schizophrenia 1 (DISC1): association with schizophrenia, schizoaffective disorder, and bipolar disorder. Am. J. Hum. Genet. 75, 862-872 (2004).

15 Thomson, P.A., Wray, N.R., Millar, J.K., Evans, K.L., Hellard, S.L., Condie, A. et al. Association between the TRAXIDISC locus and both bipolar disorder and schizophrenia in the Scottish population. Mol. Psychiatry 10, 657-668 (2005).

16 Callicott, J.H., Straub, R.E., Pezawas, L., Egan, M.F., Mattay, V.S., Hariri, A.R. et al. Variation in DISC1 affects hippocampal structure and function and increases risk for schizophrenia. Proc. Natl Acad. Sci. USA 102, 8627-8632 (2005).

17 Zhang, F., Sarginson, J., Crombie, C., Walker, St N., Clair, D. \& Shaw, D. Genetic association between schizophrenia and the DISC1 gene in the Scottish population. Am. J. Med. Genet. B. Neuropsychiatr. Genet. 141B, 155-159 (2006).

18 Nicodemus, K.K., Kolachana, B.S., Vakkalanka, R., Straub, R.E., Giegling, I., Egan, M.F. et al. Evidence for statistical epistasis between catechol-O-methyltransferase (COMT) and polymorphisms in RGS4, G72 (DAOA), GRM3, and DISC1: influence on risk of schizophrenia. Hum. Genet. 120, 889-906 (2007).

19 Wood, L.S., Pickering, E.H. \& Dechairo, B.M. Significant support for DAO as a schizophrenia susceptibility locus: Examination of five genes putatively associated with schizophrenia. Biol. Psychiatry 61, 1195-1199 (2007).

20 Song, W., Li, W., Feng, J., Heston, L.L., Scaringe, W.A. \& Sommer, S.S. Identification of high risk DISC1 structural variants with a $2 \%$ attributable risk for schizophrenia. Biochem. Biophys. Res. Commun. 367, 700-706 (2008).

21 Saetre, P., Agartz, I., De Franciscis, A., Lundmark, P., Djurovic, S., Kahler, A. et al. Association between a disrupted-in-schizophrenia 1 (DISC1) single nucleotide polymorphism and schizophrenia in a combined Scandinavian case-control sample. Schizophr. Res. 106, 237-241 (2008).

22 Betcheva, E.T., Mushiroda, T., Takahashi, A., Kubo, M., Karachanak, S.K., Zaharieva, I.T. et al. Case-control association study of 59 candidate genes reveals the DRD2 SNP rs6277 (C957T) as the only susceptibility factor for schizophrenia in the Bulgarian population. J. Hum. Genet. 54, 98-107 (2009).

23 Schosser, A., Gaysina, D., Cohen-Woods, S., Chow, P.C., Martucci, L., Craddock, N. et al. Association of DISC1 and TSNAX genes and affective disorders in the depression case-control (DeCC) and bipolar affective case-control (BACCS) studies. Mol. Psychiatry 15, 844-849 (2009).

24 Schumacher, J., Laje, G., Abou Jamra, R., Becker, T., Muhleisen, T.W., Vasilescu, C. et al. The DISC locus and schizophrenia: evidence from an association study in a central European sample and from a meta-analysis across different European samples. Hum. Mol. Genet. 18, 2719-2727 (2009).

25 Rastogi, A., Zai, C., Likhodi, O., Kennedy, J.L. \& Wong, A.H. Genetic association and post-mortem brain mRNA analysis of DISC1 and related genes in schizophrenia. Schizophr. Res. 114, 39-49 (2009).

26 Liu, Y.L, Fann, C.S., Liu, C.M., Chen, W.J., Wu, J.Y., Hung, S.I. et al. A single nucleotide polymorphism fine mapping study of chromosome 1q42.1 reveals the 
vulnerability genes for schizophrenia, GNPAT and DISC1: association with impairment of sustained attention. Biol. Psychiatry 60, 554-562 (2006).

27 Chen, Q.Y., Chen, Q., Feng, G.Y., Lindpaintner, K., Wang, L.J., Chen, Z.X. et al. Case-control association study of Disrupted-in-Schizophrenia-1 (DISC1) gene and schizophrenia in the Chinese population. J. Psychiat. Res. 41, 428-434 (2007).

28 Qu, M., Tang, F., Yue, W., Ruan, Y., Lu, T., Liu, Z. et al. Positive association of the Disrupted-in-Schizophrenia-1 gene (DISC1) with schizophrenia in the Chinese Han population. Am. J. Med. Genet. B. Neuropsychiatr. Genet. 144B, 266-270 (2007).

29 Wilson-Annan, J.C., Blackwood, D.H., Muir, W., Millar, J.K. \& Porteous, D.J. An allelic association study of two polymorphic markers in close proximity to a balanced translocation t $(1: 11)$ that co-segregates with mental illness. Psychiatr. Genet. Winter 7, 171-174 (1997).

30 Devon, R.S., Anderson, S., Teague, P.W., Burgess, P., Kipari, T.M., Semple, C.A. et al. Identification of polymorphisms within Disrupted in Schizophrenia 1 and Disrupted in Schizophrenia 2, and an investigation of their association with schizophrenia and bipolar affective disorder. Psychiatr. Genet. 11, 71-78 (2001).

31 Kockelkorn, T.T., Arai, M., Matsumoto, H. Fukuda, N., Yamada, K., Minabe, Y et al. Association study of polymorphisms in the $5^{\prime}$ upstream region of human DISC1 gene with schizophrenia. Neurosci. Lett. 368, 41-45 (2004).

32 Zhang, X., Tochigi, M., Ohashi, M., Maeda, K., Kato, T., Okazaki, Y. et al. Association study of the DISC1/TRAX locus with schizophrenia in a Japanese population. Schizophr. Res. 79, 175-180 (2005).

33 Kim, H.J., Park, H.J., Jung, K.H., Ban, J.Y., Ra, J., Kim, J.W. et al. Association study of polymorphisms between DISC1 and schizophrenia in a Korean population. Neurosci. Lett. 430, 60-63 (2008).

34 Sanders, A.R., Duan, J., Levinson, D.F., Shi, J., He, D., Hou, C. et al. No significant association of 14 candidate genes with schizophrenia in a large European ancestry sample: implications for psychiatric genetics. Am. J. Psychiatry 165, 497-506 (2008).

35 Mathieson, I., Munafo, M.R. \& Flint, J. Meta-analysis indicates that common variants at the DISC1 locus are not associated with schizophrenia. Mol. Psychiatry 17, 634-641 (2012)

36 Hennah, W., Tuulio-Henriksson, A., Paunio, T., Ekelund, J., Varilo, T., Partonen, T. et al A haplotype within the DISC1 gene is associated with visual memory functions in families with a high density of schizophrenia. Mol. Psychiatry 10, 1097-1103 (2005).

37 Cannon, T.D., Hennah, W., van Erp, T.G., Thompson, P.M., Lonnqvist, J., Huttunen, M. et al. Association of DISC1/TRAX haplotypes with schizophrenia, reduced prefrontal gray matter, and impaired short- and long-term memory. Arch. Gen. Psychiatry 62, 1205-1213 (2005)

38 Burdick, K.E., Hodgkinson, C.A., Szeszko, P.R., Lencz, T., Ekholm, J.M., Kane, J.M. et al. DISC1 and neurocognitive function in schizophrenia. NeuroReport 16, 1399-1402 (2005).

39 Tomppo, L., Hennah, W., Miettunen, J., Jarvelin, M.R., Veijola, J., Ripatti, S. et al. Association of variants in DISC1 with psychosis-related traits in a large population cohort. Arch. Gen. Psychiatry 66, 134-141 (2009).

40 Sullivan, P.F., Lin, D., Tzeng, J.Y., van den Oord, E., Perkins, D., Stroup, T.S. et al. Genomewide association for schizophrenia in the CATIE study: Results of stage 1. Mol. Psychiatry 13, 570-584 (2008).

41 Berrettini, W. Bipolar disorder and schizophrenia: not so distant relatives? World Psychiatry 2, 68-72 (2003).

42 Owen, M.J., Craddock, N. \& Jablensky, A. The genetic deconstruction of psychosis Schizophr. Bull. 33, 905-911 (2007).

43 O'Donovan, M.C., Craddock, N.J. \& Owen, M.J. Genetics of psychosis; insights from views across the genome. Hum. Genet. 126, 3-12 (2009).

44 Millar, J.K., Christie, S., Anderson, S., Lawson, D., Hsiao-Wei Loh, D., Devon, R.S. et al. Genomic structure and localisation within a linkage hotspot of Disrupted In Schizophrenia 1 , a gene disrupted by a translocation segregating with schizophrenia. Mol. Psychiatry 6, 173-178 (2001).

45 Chubb, J.E., Bradshaw, N.J., Soares, D.C., Porteous, D.J. \& Millar, J.K. The DISC locus in psychiatric illness. Mol. Psychiatry 13, 36-64 (2008).

46 Meyer, K.D. \& Morris, M.A. Disc1 regulates granule cell migration in the developing hippocampus. Hum. Mol. Genet. 18, 3286-3297 (2009).
47 Hennah, W. \& Porteous, D. The DISC1 pathway modulates expression of neurodevelopmental, synaptogenic and sensory perception genes. PLOS ONE 3, e4906 (2009).

48 Finkenstadt, P.M., Kang, W.S., Jeon, M., Taira, E., Tang, W \& Baraban, J.M. Somatodendritic localization of translin, a component of the translin/TRAX RNA binding complex. J. Neurochem. 75, 1754-1762 (2000).

49 Millar, J.K., Christie, S., Semple, C.A. \& Porteous, D.J. Chromosomal location and genomic structure of the human translin-associated factor $\mathrm{X}$ gene (TRAX; TSNAX) revealed by intergenic splicing to DISC1, a gene disrupted by a translocation segregating with Schizophrenia. Genomics 67, 69-77 (2000).

50 Nurnberger, Jr J.I., Blehar, M.C. Kaufmann, C.A., York-Cooler, C., Simpson, S.G., Harkavy-Friedman, J. et al. Diagnostic interview for genetic studies. Rationale, unique features, and training. NIMH Genetics Initiative. Arch. Gen. Psychiatry 51, 849-859 (1994).

51 American Psychiatric Association Diagnostic and Statistical Manual of Mental Disorders. 4th edition (American Psychiatric. Association Press, Washington DC, 1994).

52 Goldberg, D. P., Gater, R., Sartorius, N., Ustun, T. B., Piccinelli, M., Gureje, O. et al. The validity of two versions of the GHQ in the WHO study of mental illness in general health care. Psychol. Med. 27, 191-197 (1997).

53 Miller, S.A., Dykes, D.D. \& Polesky, H.F. A simple salting out procedure for extracting DNA from human nucleated cells. Nucleic Acids Res. 16, 1215 (1988).

54 Schmid, C.W. Alu: a parasite's parasite? Nat. Genet. 35, 15-16 (2003).

55 Arndt, P.F., Petrov, D.A. \& Hwa, T. Distinct changes of genomic biases in nucleotide substitution at the time of mammalian radiation. Mol. Biol. Evol. 20, 1887-1896 (2003).

56 Watkins, W.S., Rogers, A.R., Ostler, C.T., Wooding, S., Bamshad, M.J., Brassington, A.M. et al. Genetic variation among world populations: Inferences from 100 Alu insertion polymorphisms. Genome Res. 13, 1607-1618 (2003).

57 Barrett, J.C., Fry, B., Maller, J. \& Daly, M.J. Haploview: analysis and visualization of LD and haplotype maps. Bioinformatics 21, 263-265 (2005).

58 Palo, O.M., Antila, M. Silander, K., Hennah, W., Kilpinen, $H$., Soronen, P. et al. Association of distinct allelic haplotypes of DISC1 with psychotic and bipolar spectrum disorders and with underlying cognitive impairments. Hum. Mol. Genet 16, 2517-2528 (2007)

59 Benjamini, Y. \& Hochberg, Y. Controlling the False Discovery Rate: a practical and powerful approach to multiple testing. J. R. Statist. Soc. B 57, 289-300 (1995).

60 Hashimoto, R., Numakawa, T., Ohnishi, T., Kumamaru, E., Yagasaki, Y., Ishimoto, T. et al. Impact of the DISC1 Ser704Cys polymorphism on risk for major depression, brain morphology and ERK signaling. Hum. Mol. Genet. 15, 3024-3033 (2006).

61 Prata, D.P., Mechelli, A., Fu, C.H., Picchioni, M., Kane, F., Kalidindi, S. et al. Effect of disrupted-in-schizophrenia-1 on pre-frontal cortical function. Mol. Psychiatry 13, 915-917 (2008)

62 Nakata, K., Lipska, B.K., Hyde, T.M., Ye, T., Newburn, E.N., Morita, Y. et al. DISC1 splice variants are upregulated in schizophrenia and associated with risk polymorphisms. Proc. Natl Acad. Sci. USA 106, 15873-15878 (2009).

63 Patsopoulos, N.A., Tatsioni, A. \& Loannidis, J.P. Claims of sex differences: an empirical assessment in genetic associations. JAMA 298, 880-893 (2007).

64 Lin, P.I., Vance, J.M., Pericak-Vance, M.A. \& Martin, E.R. No gene is an island: the flipflop phenomenon. Am. J. Hum. Genet. 80, 531-538 (2007).

65 Hattori, E., Toyota, T., Ishitsuka, Y., Iwayama, Y., Yamada, K., Ujike, H. et al. Preliminary genome-wide association study of bipolar disorder in Japanese population. Am. J. Med. Genet. B. Neuropsychiatr. Genet. 150B, 1110-1117 (2009).

66 Liu, Y., Chen, G., Norton, N., Liu, W., Zhu, H., Zhou, P. et al. Whole genome association study in a homogenous population in Shandong peninsula of China reveals JARID2 as a susceptibility gene for schizophrenia. J. Biomed. Biotechnol. 2009, 536918 (2009).

67 Amagane, H., Watanabe, Y., Kaneko, N., Nunokawa, A., Muratake, T., Ishiguro, H. et al. Failure to find an association between myosin heavy chain 9, non-muscle (MYH9) and schizophrenia: a three-stage case-control association study. Schizophr. Res. 118 106-112 (2010)

68 Rosenberg, N.A., Huang, L., Jewett, E.M., Szpiech, Z.A., Jankovic, I. \& Boehnke, M. Genome-wide association studies in diverse populations. Nat. Rev. Genet. 11 356-366 (2010).

Supplementary Information accompanies the paper on Journal of Human Genetics website (http://www.nature.com/jhg) 